\section{Clinitral apceture}

ON

\section{THE SUCCESSFUL USE OF IODIDE OF POTASSIUM IN THE TREATMENT OF ANEURISM.}

\author{
LY \\ WILLIAM ROBERTS, M.D., \\ PHYSICIAN TO THE MANCHESTER ROYAL INFIRMARY.
}

[Reprited by M[r. E. ]Awson, Clinical Clerk.]

Genthemex,-I propose to draw your attention today to a case of thoracic aneurism, which has been under my care, in No. $68 \mathrm{Ward}$, for the last six weeks.

The case affords an advantageous example for the illustration of the various points of importance in the diagnosis of aortic ancurism; but I shall pass orcr these with only a brief recital, in order to bring before you at length certain points of interest bearing on the use of iodide of potassium in the treatment of ancurism.

J. P., a collier, aged 39 , unmarried, was admitted into the Poyal Infirmary, on October 6th, 1862 , complaining of pain in the chest, a troublesome cough, and difficulty of breathing at night. He stated that about four months ago, when in a state of intoxication, he was kicked in the chest by a policeman. From that time he has been subject to paroxysms of excessively severe pain, persisting for several hours at a time, in the back, neck, and running up to the left side of the head and left shoulder. He compared the pain in the latter situation to having pieces of his flesh torn out. There has not been hæmoptysis at any time. About two months after the above occurrence, he observed an unnatural prominence of the upper part of the sternum.

When admitted, the patient had the appearance of good bealth; the pulse was 96 , and the respirations were 22 per minute. 'The superficial veins of the upper arms, and the exteruul jugulars were somewhat distended the right radial pulse was slightly feebler than the left. The speaking voice was unaltered, but the cough-voice possessed the peculiar stridulous character distinctive of interference with the function of the recurrent laryngeal verves.

The pupil of the left eye was motionless from previous accident, the right pupil was natural. There was some dysphagia - when the chest was uncovered, the first bone of the sternum and its immediate vicinities were ob. served to be bulged out, and to be the seat of a heaving pulsation. On the left side of this prominence, in the second intercostal space, close to the sternum, there was a soft pulsating elevation standing out about a quarter of an inch above the surrounding level. This elevation was conical in shape, and had a base about the size of a shilling. 'The heart's apex beat in the fifth interspace within the nipple line.

Percussion revealed a considerable area of diminished resonance over the bulging parts. Transversely, in the level of the second interspaces, the dulness measured four inches and a half, extending more to the left than the right of the middile line; vertically, there was dulness for three inches and a half below the sternal notch. There was no fulness or pulsation in the last named spot. The cardiac sounds were normal over the precordial region; they were loudly audible over the seat of dulness above described.

The first sound was faintly murmurish over the soft elevation; and a distinct though faint systolic murmur existed in the course of the innominate artery; this was intensified over the right carotid and in the acromial angle. No murmur existed over the left carotid and subclavian. With such an array of symptoms and physical signs, the diagnosis could not remain for a moment doubtful. The case was one of aneurism of the arch of the aorta making its way forward through the parietes of the chest.

On October 10th, the patient was ordered to take five grains of iodide of potassium three times a day; to keep his bed; and to restrain as much as possible the quantity of liquids taken in the way of drink. Three days later the iodide was increased to seven grains and a half three times a day. Six days after the commencement of the treatment, the patient reported himself a great deal better; the paroxysms of pain no longer recurred; the cough and difficulty of breathing were less troublesome; and the soft pulsating elevation was slightly less prominent. The physical signs remained otherwise unchanged. The iodide was now increased to ten grains three times a day.

From this date (October 1 (6th), to October 2 7 th (a period of eleven days) the patient went on favourably. He continued free from pain, difficulty of breathing, and dysphagia; and the soft elevation had almost altogether subsided to the level of the surrounding parts.

$\mathrm{He}$ was now allowed to get up, and the restrictions as to fluids were relaxed. The iodide was increased to fifteen grains three times a day.

On November 4 th (twenty-fifth day of treatment), the dulness measured four inches across, and two inches and three-quarters vertically. The dose was now raised to twenty grains.

On November 18th (thirty-ninth day of treatment) the area of dulness was carefully measured again. It had now contracted to three inches and three quarters transversely, and two inches and a half vertically; so that from the commencement of the treatment, it had diminished three-quarters of an inch in one direction, and one inch in the other. The soft elevation had sunk to the level of the surrounding parts, and had become wholly inappreciable to the eye. Pulsation was still felt over the spot. The patient was free from pain and difficulty of breathing, and felt himself exceedingly well. The cough was still stridulous in character, and the veins of the neck and upper arms were not perceptibly less distended. The inequality of the radial pulses had not disappeared.

This is the sum of the improvement after a treatment of six weeks ; and it is certainly a striking result in so unmanageable a disorder as a protruding aneurism of the arch of the aorta.

[Since the delivery of this lecture the patient has continued the use of the iodide of potassium up to the present time (Dec. 2:3). An obstinate diarrhœa necessitated the diminution of the iodide to five grains three times a day. The bulging of the first bone of the sternum is conspicuously less, and the limits of dulness correspond to the following dimensions: transversely, three inches and a half; vertically, two inches and a quarter.

The state of the radial pulses, and of the superficial veins of the neck and arms, together with the character of the voice, remain unaltered; and there is decided emaciation.]

I will now relate to you the history of two other cases, within my knowledge, of aneurism treated with iodide of potassium.

About a twelvemonth ago, I saw in consultation with Mr. T. Windsor, who first called my attention to this mode of treating aneurism, a lady, 29 years of age, suffering from an undoubted aneurism of the arch of the 
aorta, implicating the commencement of the arteria in nominata. There were violent pains on the right side of the head, paroxysmal dyspnoa, excessive pulsation at the root of the neck on the right side, and sleeplessness. A dull space extended from a little to the inside of the right sterno-clavicular articulation for a distance of two inches outward. Over this space there was a heaving pulsation. No murmur existed with either sound; but the sounds were intensified over the arch, and towards the clavicle. Repeated slight hæmoptysis had been observed.

For an account of the further progress of the case, and the treatment, I am indebted to Mr. Windsor.

In the succeeding six months the condition of the patient become steadily aggravated in spite of a perse vering observance of the recumbent posture and a re gulated diet. On several occasions the voice was tem porarily lost; in addition to some dysphagia, there was constant troublesome cough, with tenacious scanty $\mathrm{ex}$ pectoration, and occasionally severe paroxysms. The difficulty of breathing and pains were often so severe, that the patient was forced to quit her bed, and to walk about. She had become considerably emaciated, and so weak as to be unable to leave her room. The clavicle also began to project, and at length stood out half an inch beyond its natural level. 'The pulsation at the root of the neck increased; and the right eye became the seat of a severe congestion.

The iodide of potassium was first administered in April last in the hope of diminishing the pains in the head. The desired effect was speedily produced; and the medicine was discontinued after it had been used a week. In July, the patient growing daily worse, and fatal termination appearing not to be very far off, $\mathrm{Mr}$. Windsor again administered iodide of potassium in doses of five grains three times a day. 'This quantity was shortly after increased to ten grains; but owing to the occurrence of violent salivation, the dose was again brought down to five grains. This quantity agreed; and the patient has been taking it until the present time, with great benefit, as you shall hear. The general symptoms subsided quickly; the cough, pain, dyspnwa, and dysphagia, disappeared; the occasional hemoptysis ceased to recur; the patient gained flesh and strength, and two months ago she was able to walk six miles; and, more important than all, the projection of the clavicle progressively receded, until it has now almost gone back to its natural position.

The third case which has come under my personal notice is a patient of my colleague Dr. Wilkinson.

This man was admitted into the infirmary on October 20 th, with a thoracic aneurism coming forward in the neck. In a few days, it formed a tumour as large as a child's head, extending on the left side from the clavicle almost to the angle of the jaw, causing very great distress; and passing on to what appeared a speedy termination by rupture. This man was put under gradually increasing doses of the iodide of potassium until the quantity attained was fifteen grains three times a day. No positive amelioration can be said to have taken place in the condition of the aneurism; but the distress is scarcely so great as it was, and the rapid growth of the tumour seems to have been stayed.

[Seventeen days after the delivery of the lecture, Dr. Wilkinson's patient died. Death took place from pressure of the tumour on the left pneumogastric nerve, and conse quent pulmonary mischief. The vagus trunk was thattened out and atrophied for the space of an inch and a half in the neck. Only a few nerve-tubules could be discovered in this part by the microscope. The left lun. was the seat of several patches of gangrene as large as hen's eggs, surrounded by areas of consolidation. The pulmonary gangren $\theta$ had been detected a week before death. The sac of the aneurism was lined with thick layers of coagulated fibrine; and a large firm blanched clot attached by a somewhat broad pedicle to the upper parts of the parietes, floated freely in the sac.]

So far as I know, the first notice of the use of iodide of potassium in aneurism occurs in a clinical lecture of Professor Nélaton (Clinique Éuiopéenne, July 1859). M. Nélaton had been consulted by a Pole on account of a tumour in the lower part of the neck. Several physicians of eminence, Bouilland, Andral, Beau, had previously seen the case, and had diagnosticated an aneurism of the innominate artery or of the aorta. 'The patient stated that while residing in Warsaw, iodide of potassium had been administered to him with great relief. Nélaton took the hint, and prescribed the same. To his astonishment, a very notable amelioration followed, which went on almost to complete disappearance of the tumour, and the patient returned to his country in a satisfactory state of health.

In a late number of the same journal (Aug. 27th, ] 859), you may find a very brief account of a number of cases by Bouillaud. One was a woman with aneurism of the carotid artery. Iodide of potassium was administered in riamme doses; then in twogramme doses for two months. At the end of that time, the tumour, previously as large as a pigeon's egg, had diminished almost to disappearance. The second was an aneurism of the aorta and innominate in a man. The tumour, which had a very considerable volume, had suffered displacement and very great diminution of size under iodide of potassium. The case was under treatment when reported.

A third instance related to a large aneurism at the point of origin of the carotid and subclavian. The tumour had diminished considerably in a few weeks under the iodide.

A colonel with an aneurism of the carotid furnishes a fourth case in which Bouillaud saw the tumour almost wholly disappear after taking the same drug.

The next reference to the subject comes from a wholly independent source, and is, for that reason, of additional value. It occurs in a paper by $\mathrm{Dr}$. Chuckerbutty of Calcutta, published in the BRITISH Medical Journal for July 1862. He gives an account of four cases.

The first of these was an aneurism of the innominate artery growing steadily upward into the neck. The growth ceased on the administration of iodide of potassium in decoction of cinchona, and the sac gradually solidified. The patient, however, was carried off, some months afterwards, by an attack of bronchitis. The autopsy revealed a sac as large as a pear, filled with dense coagula, leaving merely a narrow channel on the outer aspect, through which the right carotid and subclavian arteries communicated with the aorta.

In a second case, marked temporary relief followed the administration of the iodide in an immense aneurism of the aorta. The aneurism finally destroyed the paticnt by rupture. A post mortem examination three hours after death showed the sac to be filled with dense, solid coagula.

In a third case of large aortic aneurism, temporary amendment took place so far that the patient left the hospital, considering himself cured. Three months later, he returned, with intense aggravation of all his symptoms, and died in a few days. 
In the fourth example, an aortic aneurism which formed a dome-shaped tumour two inches in diameter, coming forward through the sternum, had been treated in vain by turpentine, sulphuric acid, and other remedies. After the administration of iodide of potassium internally, and the application of the tincture of iodine externally, the patient steadily improved in every respect ; the thoracic pain disappeared, the swelling diminished, the hæmoptysis ceased, and the patient ate and slept like any other man. He was still under treatment.

I do not wish to make too much of those facts. The erratic course of aneurismal tumours, and the occasional occurrence of spontaneous consolidation of their sacs are well known. Nevertheless, the twelve cases here brought togrether form a very remarkable series. In all of them, save one, striking relief of suffering followed the use of the drug ; in eight, an undoubted diminution of the size of the sac took place; and in a few, complete subsidence of the swelling seems to have occurred.

The cases of Dr. Chuckerbutty would appear to indicate that the beneficial effect of the iodide was owing to its power (hitherto wholly unsuspected) of increasing the coagulability of the blood. Dr. Wilkinson's case lends support to this view; for not only was the sac lined with layers of fibrine, but a very firm, decolorised, fibrinous mass, attached on one side, floated in the cavity of the aneurism. The value of the above observations, as bearing on the conclusion inferred, is greatly increased by the circurnstance that they are derived from two distinct and wholly independent sourees.

Enough has certainly been advanced to encourage an inquiry into the power of iodide of potassium as a general homostatic; and to demand a fuller trial of its effects in internal and external aneurisms; in the treatment of which no internal remedy hitherio employed has succeeded in gaining eren a temporary footing.

Use of Conipressed Sponge in the Prevention of Lactear Secretion. Dr. P. Stewart of Peekskill, New York, states that three years ago, he reported in the New York Journal of Medicine a case of suppression of the lacteal secretion, in the breast of a lady recently confined, by means of compressed sponge and handage. Since the report of this case, he has several times had occasion to adopt the same practice, and uniformly with the same happy result. If others have used the method it has fuiled to come to his knowledge, and as the remedy is easily applied, and the results in his hands, at least, unifurmly successful, it may be of some little service, he thinks, to call the attention of the profession once more very briefly to the subject. A flat solt sponge, carefully freed from all foreign substances, large enough to cover the entire breast, with a small hole or depression cut out in the centre $f(r)$ the ripple, is suljected to a pressure of a few pounds for a couple of days, and then applied over the breast; a compress is laid over this, and the whole secured by a bandage passed over the shoulders, and around the waist, so as to produce equal and uniform pressure over the entire surface. The bandage should be tightened sufficiently often to maintain a constant pressure for twolve or fourteen days. The best time to begin the treatment is wihin twelve hours after the birth, when the sponge is best applied dry; but if it is delayed from any cause until the breast becomes tender, and the milk begins to be secreted, Dr. Stewari's custom is to dip it in warm vinegar once or twice a day. (American Medical Times.)

\section{Adotresses and opers}

\section{THE TIIIRTIETI ANNUAL MEETING OE THE BRITISH MEDICAL ASSOCIATION.}

[Held in LONDON, ALGUST 5th, 6th, rth, and 8th, 1862.]

\section{OBSERVATIONS ON TIIE OCCURRENCE OF MALIGNANT PUSTULE IN ENGLAND : ILLUSTRATED BY NUMEROUS FATAL CASES. \\ Dy WILLTAMI BUDD, M.D., Clifton; Honorary and} Consulting Physician to the Bristol Royal

$$
\text { Infirmary. }
$$

"Le médecin doit, dans ses premières études, jetcr un coup d'œil sur les animanx qui se rapprochent le plus de l'homme."-Chaussicr. (Adopted from Régnier.)

IN France, Germany, Russia, Lapland, Sweden, Italy, and other parts of Europe, under the characteristic name of Maligrant Pustule, a disease has long been familiarly known and described, which proves fatal every year to a large number of persons.

Beginning as a minute vesicle, which is seated always on some uncovered part, its special character is to excite a peculiar form of gangrenous inflammation, which, spreading rapidly from the point first affected to the neighbouring tissues, gives rise to local changes of very uncommon aspect, and finally destroys life by general infection.

A discase calculated, by so much that is striking, to arrest attention, has, naturally, been maae an object of inquiry by many eminent observers.

Among other distinguished men, Vallisneri, Solander, Pallas, Fournier, Thomassin, Chabert, Kausch, Malacarne, Linnæus,* Glanström, Enaux and Chaussier, Leuret, Delpech, Rayer, Bourgeois, Salmon and Maunory, Hoffmann, and Heusinger, may be specially mentioned as having each contributed something to its history.t

* Iinnaus, who was himself attacked by the disease, but happily recovered, was the first to give authentic evidence of the cxistence of malignant pustule in Lapland.

+ iallisncri. Lettere spettanti alla storia medica é naturale. ladura (1713). Also, Nuova idea del mal contagioso de buoi. (1714.) Sulander, I). Clir. Furia infermalis. Nov. Act. Upsal. Tom. i, 113. (1; r 3.) Pallas, $I^{2} . F$. Vergleichnung einiger in Schweden, liussland, und siberien, und den daran grenzenden Wiisteneien bemerkten tödlichen Krankheiten, die man füglich unter den Namen, Brandbeulen, zusammentassen kam. Neue nordische Breitr. B. 1, p.113. Fournicr. Observations et experiences sur les Charbons mulins. Jijon: 1ilig. Thomassin. Dissertation sur le Charbon main de la Jouragne, ou de la pustule maligne. Dijon: 17 80 Chalicht. Description et iraitement du Charbon. Paris: 1780 Kausch. Dic in Küuigreich l'reussen und besouders in Ileyogthum Wurs. In Writion

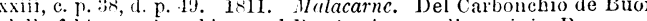
della febtre carbonchiosa nel Bestianie e negli nomin. Bassano 797. Linnaus. Ampnitates Academicm. Vol. iii, r. 322. Glansï̈m. Dissertatio de pustula livida. Regiomonti: 1s24. Enaux ct Ghaussicr. Metbode de traiter les morsures des animaux enragis, et de la vipere. suivi d'un préeis sur la pustule maligne. Dijon: 1:5.5. Rayer. 'Traité des Maladies de la l'eau. Article, Pustule Mnlione. Pourqcois. Memnire sur la Pustule Mulione. (Archices Ginirales de la Hedecine. tme series, t. 1, p. 172.) Salmon ct Mranory. Memoire sur linoculation de la pustule ma-

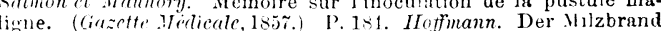

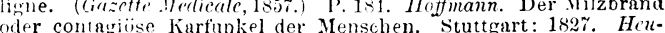
oder conlagiose Karfunkel der Menschen. Stutgart: 1827. Hen-
singer. Die Hilzbrand.Krankheiten der Thiere und des Menschen. Eriangen: 1850 . Some of these authorities I have studied in the 